\title{
RANCANG BANGUN SUPPORTING AND SAFETY EQUIPMENT PADA MESIN ROBOT DRAWING HYBRID LASER
}

\author{
SUMARNO ${ }^{1}$, AMIR $^{2}$, SETIAWAN AGUS SAPUTRA ${ }^{3}$ \\ Program Studi Teknik Mesin, Fakultas Teknik, Universitas Muhammadiyah Tangerang \\ Jl. Perintis Kemerdekaan I/33 Cikokol-Tangerang \\ E-Mail : bagosumarno76@gmail.com
}

\begin{abstract}
ABSTRAK
Penggunaan teknologi laser sebagai marking pada alat-alat rumah tangga maupun industri mengalami peningkatan yang cukup signifikan. Dengan berlatar belakang hal tersebut saya dan tim menyusun sebuah karya tulis yang membahas tentang laser dan grafir khususnya mengenai komponen pendukung atau supporting equipment mesin ini. Penelitian yang sifatnya rancang bangun ini bertujuan agar pembaca dapat memahami proses perancangan desain hingga fabrikasi serta analisis dari komponen pendukung mesin Robot drawing hybrid laser. Penelitian ini menggunakan metode studi literatur, observasi, perancangan desain, fabrikasi dan analisis hasil. Observasi ditekankan pada pengukuran dan pengkajian mesin utama Robot drawing hybrid laser. Perancangan desain dibantu oleh software pendukung yaitu Autodesk Inventor dan Autocad. Fabrikasi meliputi proses cutting, setting, welding dan finishing. Output penelitian ini berupa sebuah perangkat mesin yang siap untuk dioperasikan lengkap dengan komponen pendukungnya berupa meja kerja, safety cover, dan papan instruksi. Ketika mengoperasikan mesin ini operator akan merasa nyaman sehingga produktivitasnya pun tinggi.
\end{abstract}

Kata kunci: rancang bangun, supporting equipment, safety, robot drawing hybrid laser, autodesk inventor.

\begin{abstract}
The use of laser technology as marking on household and industrial appliances has increased significantly. With this background, my team and I compiled a paper that discussed lasers and engraving, especially regarding the supporting components or supporting equipment of this machine. This research, which is design in nature, aims to enable readers to understand the design process from design to fabrication as well as analysis of the supporting components of the hybrid laser drawing robot frame. This research uses the method of literature study, observation, design design, fabrication and analysis of results. Observation is emphasized on the measurement and assessment of the main machine Hybrid laser drawing robot. The design is assisted by supporting software, namely Autodesk Inventor and Autocad. Fabrication includes cutting, setting, welding and finishing processes. The output of this research is a machine that is ready to be operated complete with its supporting components in the form of a work table, safety cover, and instruction board. When operating this machine the operator will feel comfortable so that the productivity is high.
\end{abstract}

Keywords: design, supporting equipment, safety, hybrid laser drawing robot, autodesk inventor.

\section{PENDAHULUAN}

Rancang bangun ini bertujuan untuk mengimplementasikan Mesin Computer Numerical Control (CNC) yang murah, dengan ukuran yang lebih kecil, mudah dioperasikan, dan fleksibel sekaligus bisa untuk laser grafir dan juga pen drawing untuk pemodelanya 2 in 1 bisa digunakan keduanya dengan satu alat. Sebagai sumbu penggeraknya ada dua sumbu X, Y. Pada desain Mesin ini Terdapat 2 Motor Stepper. Motor Stepper digunakan untuk mengontrol gerakan benda pada sumbu X dan Y untuk menggerakkan pulpen atau laser grafir. Mikrokontroler Arduino Uno cnc shield v3, DRV8825 yang diintegrasikan dengan modul CNC Shield digunakan untuk mengontrol sinkronisasi secara tepat dari kedua
Motor Stepper nema 17 selama proses pencetakan/menggambar. Arduino Uno diprogram dengan menggunakan bahasa G-Code dari komputer yang terhubung ke Arduino melalui kabel USB dengan bantuan software Inkscape dan GBRL laser untuk mengontrol pergerakan dan sinkronisasi motor. Mesin pulpen drawing diimplementasikan dan diuji dengan mencetak logo yang berisikan gambar dan tulisan pada kertas foto $(180 \mathrm{~mm} \times 120 \mathrm{~mm})$ dengan menggunakan ballpoint . Sedangkan untuk laser grafir dingunakan untuk mencatak marking nama atau logo dan lain - lain untuk medianya kayu, mdf, dan kertas. Untuk menunjang kinerja dari mesin utama perlu disiapkan perangkat pendukung yang akan membantu operator dalam 
pengoperasian mesin ini. Berdasarkan latar belakang tersebut, maka penyusun mengambil judul "Rancang Bangun Supporting And Safety Equipment pada Mesin Robot Drawing Hybrid Laser."

\section{METODOLOGI PENELITIAN 2.1 Diagram Alir}

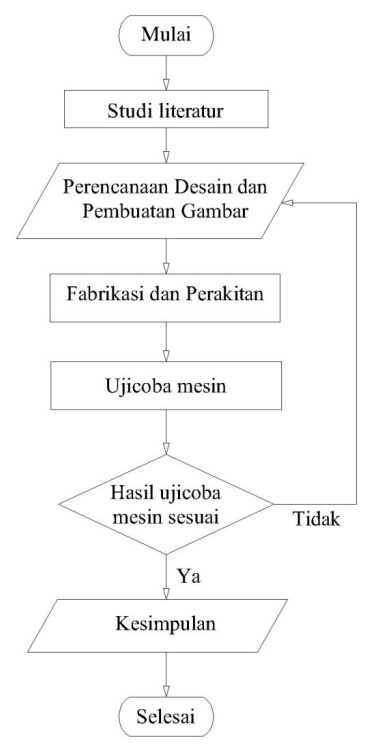

\section{Gambar 1. Diagram Alir}

\subsection{Alat Pendukung Rancang Bangun}

1. Tahap Pengambilan Data

Pada tahap ini diperlukan beberapa alat pendukung yang digunakan sebagai penunjang penelitian, diantaranya adalah: meteran, jangka sorong, mistar dan alat tulis.

2. Tahap Perancangan Desain

Pada tahap ini alat pendukung yang dibutuhkan diantaranya adalah: computer, software autodesk inventor, software autocad, printer, flashdisk dan kertas A4.

3. Tahap Fabrikasi dan Perakitan

Alat pendukung proses fabrikasi dan perakitan adalah: mesin las, mesin gerinda tangan, gergaji mesin, mesin bor, mata bor, kunci pas, obeng, pengamplas, siku, penitik, mesin tap, tang dan tang rivet

\subsection{Mesin Robot Drawing Hybrid Laser}

Alat yang memiliki 2 fungsi sekaligus yaitu digunakan untuk membuat tulisan, objek, pola, atau gambar menggunakan pulpen dan laser yang terpasang pada sumbu Y. Alat ini memiliki 2 sumbu yaitu $\mathrm{X}$ dan $\mathrm{Y}$. Dalam bekerjanya Mesin ini menggunakan kontroler : Arduino Uno, CNC Shield V3, DRV 8825. Mekanisme penggeraknya menggunakan 2 buah motor servo jenis Nema 17. Power suplainya DC 12V 5A. Untuk lasernya berkekuatan $1000 \mathrm{~mW}$. Dalam mencetaknya alat ini berkapasitas maksimal $\mathrm{X}: 33 \mathrm{~cm}$ dan $\mathrm{Y}: 23 \mathrm{~cm}$. Untuk aplikasi desainnya menggunakan software Inkscape dan dalam pengoperasiannya menggunakan software Laser GRBL.

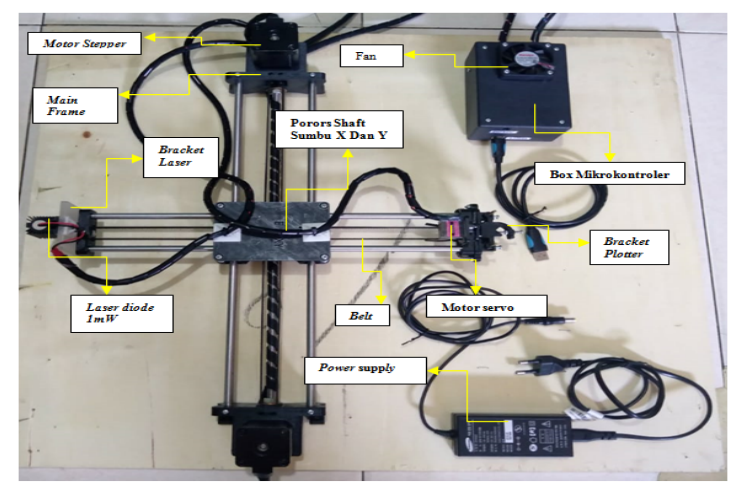

Gambar 2. Robot Drawing Hybrid Laser

\section{HASIL DAN PEMBAHASAN}

\subsection{Penerapan Software Inventor Untuk Pembuatan Desain Safety \& Supporting Equipment Pada Mesin Robot drawing hybrid laser}

Hasil dari analisis terkait penerapan software Autodesk Inventor untuk pembuatan desain Safety \& Supporting Equipment pada mesin Robot drawing hybrid laser:

1. Gambar Komponen Utama Mesin Robot drawing hybrid laser

Melalui software Autodesk Inventor, komponen utama robot drawing hybrid laser digambarkan menjadi beberapa pandangan. Hal tersebut bertujuan agar saya dapat melakukan analisis secara dimensional dari komponen utama tersebut. Gambar 3 tampak atas dari komponen utama Robot drawing hybrid laser .

Dari gambar paling luar dari komponen utama mesin robot drawing hybrid laser. Ukuran yang tampak dari software Autodesk Inventor tersebut menggunakan satuan millimeter (mm). Pada salah satu sisi gambar tampak garis putusputus yang menunjukkan simulasi pergerakan dari robot drawing hybrid laser pada sumbu $Y$. 


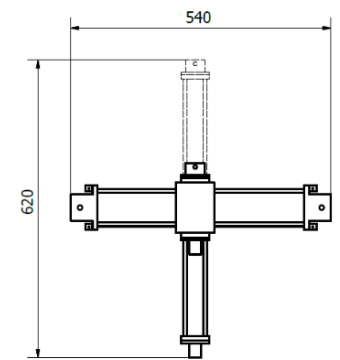

Gambar 3. Tampak Atas Drawing Hybrid Laser

Di bawah ini adalah gambar tampak depan dari komponen utama mesin:

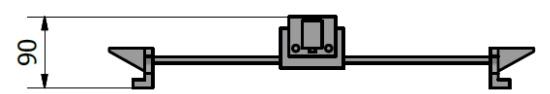

\section{Gambar 4. Tampak depan Robot Drawing Hybrid Laser}

Pada gambar di atas tampak ukuran tinggi total komponen utama mesin robot drawing hybrid laser. Ukuran tersebut akan menjadi patokan untuk menentukan desain cover mesin. Selain pandangan atas dan depan dari software Autodesk Inventor juga dapat dibuat pandangan 3D. Dengan pandangan 3D, bentuk mesin akan semakin terlihat jelas.

Pandangan 3D dari mesin robot drawing hybrid laser adalah sebagai berikut:

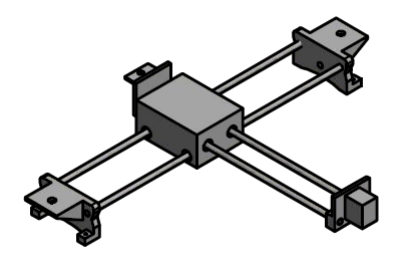

\section{Gambar 5. Tampak 3D Robot Drawing Hybrid Laser}

2. Desain Meja Mesin

Pada langkah nomor satu telah dijelaskan ukuran komponen mesin utama robot drawing hybrid laser. Selanjutnya dari data tersebut dapat direncanakan desain meja mesin. Meja mesin akan dibuat dengan ukuran panjang $700 \mathrm{~mm}$ dan lebar $650 \mathrm{~mm}$. Ukuran ini diambil dari ukuran panjang $\mathrm{x}$ lebar mesin Robot drawing hybrid laser dengan memberikan jarak aman di setiap sisi meja. Gambar tampak atas meja mesin adalah sebagai berikut :

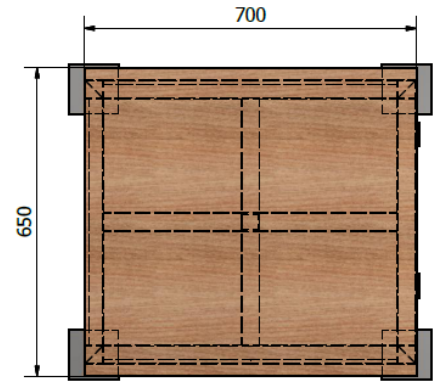

\section{Gambar 6. Tampak Atas Meja Mesin}

Ketinggian meja mesin adalah $800 \mathrm{~mm}$. Ukuran tinggi tersebut dinilai sangat ideal bagi operator dalam menjalankan mesin. Kerangka atau frame mesin akan dibuat menggunakan bahan besi Mild Steel dengan profil kotak atau Hollow. Ukuran yang dipilih adalah 40 x $40 \mathrm{~mm}$ dengan tebal $2 \mathrm{~mm}$. Penggunaan bahan tersebut memberikan kesan rapih dan kokoh.

Sebagai alas atau dudukan mesin di bagian atas meja menggunakan bahan papan MDF. Kerataan dan kehalusan bahan ini sangat cocok sebagai tempat menaruh benda kerja. Selain itu bahan ini juga tidak terlalu berat sehingga meja mesin mudah dipindahkan ketika mobilisasi.

Pada bagian bawah meja diberikan aksesoris roda berukuran 2 inchi. Tipe roda adalah swivel (dapat berputar mengikuti kemudi) sehingga ketika mobilisasi mudah untuk berbelok mengikuti atau menyesuaikan jalan.

Meja dilengkapi dengan handle pada Gambar 7 yang digunakan untuk pegangan ketika menarik atau mendoronng meja. Handle dibuat dari pipa yang berukuran sesuai dengan kenyamanan operator.

Area di bawah meja dimanfaatkan untuk tempat penyimpanan barang-barang pendukung mesin seperti netbook, benda kerja, dan lain-lain. Sebagai penutup dan alas dari lemari penyimpanan tersebut, saya menggunakan papan triplek dengan tebal $8 \mathrm{~mm}$. Pada bagian alas diperhitungkan desain frame yang mampu menahan beban yang direncanakan. 


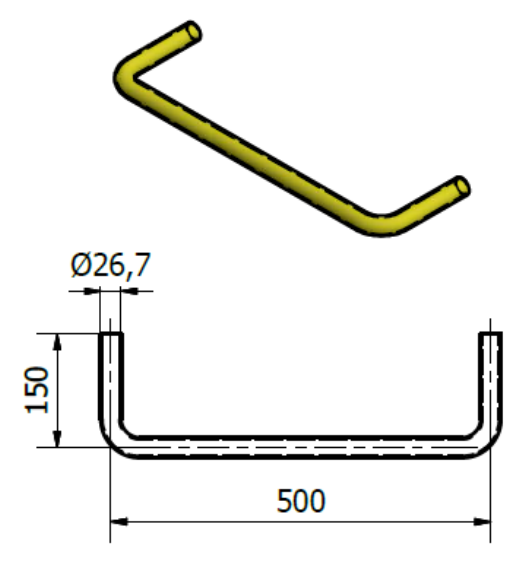

Gambar 7. Detail Handel

Rincian perhitungan kekuatan frame tersebut dapat dilihat pada simulasi menggunakan software Inventor berikut:

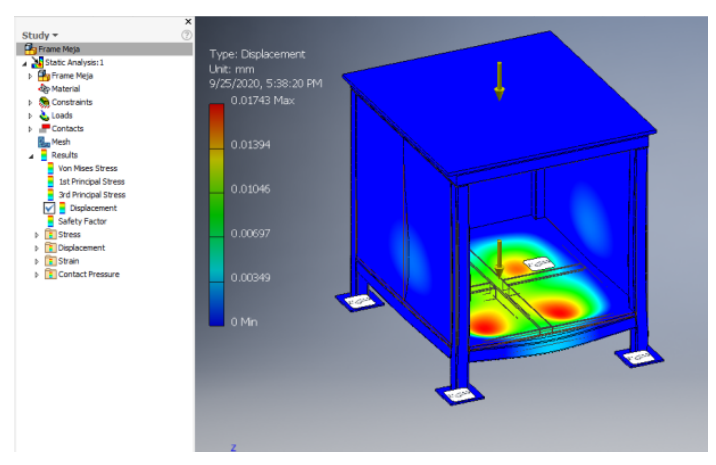

\section{Gambar 8. Simulasi Frame Meja Mesin}

Pada sisi depan meja dibuatkan meja untuk tempat notebook. Meja tersebut diambil dari dinding lemari sisi depan yang diberi engsel dan penahan. Untuk memahami lebih jelas desain dari komponen ini kita dapat melihat gambar tampak samping dan 3D berikut :

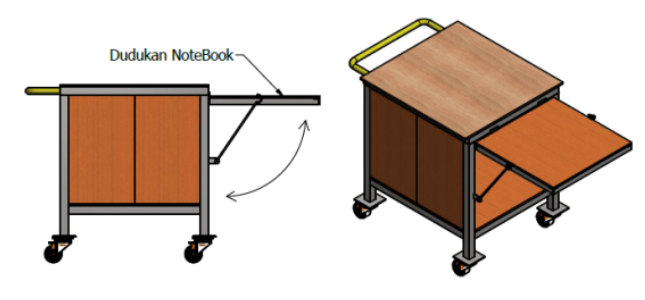

Gambar 9. Desain Dudukan Notebook
3. Desain Papan Instruksi

Dengan software Autodesk Inventor ukuran papan instruksi disimulasikan agar sesuai dengan kebutuhan. Dalam membuat desain papan instruksi, juga diperhatikan koneksi ke meja mesin. Untuk memudahkan pada saat mobilisasi, koneksi papan instruksi dengan meja menggunakan sistem knockdown (mur baut). Untuk mengetahui lebih jelas langkah-langkah pembuatan desain papan instruksi maka saya menjabarkannya sebagai berikut:

a. Menentukan apa saja yang akan dimuat dalam papan instruksi

Informasi yang akan dimuat di papan instruksi diantaranya adalah nama mesin, nama pembuat atau peneliti mesin, nama Universitas, dan tahun pembuatan. Selain itu dimuat juga langkah-langkah atau prosedur pengoperasian mesin. Pemilihan warna latar belakang papan instruksi dibuat supaya operator mudah dalam pengoperasian mesin.

b. Penentuan ukuran papan instruksi melalui simulasi pada gambar

Item-item yang disebutkan pada pembahasan sebelumnya disusun ke dalam satu area persegi lengkap dengan ukurannya. Dari simulasi susunan akan menghasilkan ukuran papan instruksi yang dibutuhkan.

c. Pembuatan desain dan gambar papan instruksi

Setelah mendapatkan ukuran yang sudah sesuai dengan ukuran, papan instruki kemudian disketsakan dalam bentuk gambar. Papan instruksi dipasang dengan posisi vertical sehingga perlu dibuat frame penyangganya. Frame tersebut di bagian dimanfaatkan sebagai tempat lampu. Gambar assembly papan instruksi dapat dilihat di bawah ini :

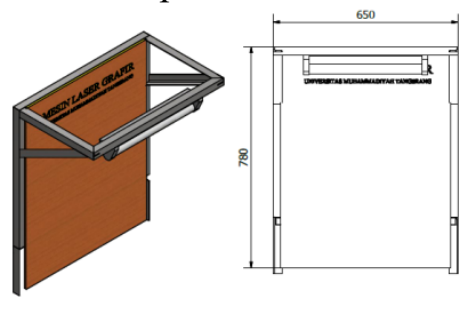

Gambar 10. Desain Papan Intruksi 
4. Desain Cover Mesin

Penerapan software untuk pembuatan desain cover mesin yang pertama adalah untuk melakukan simulasi letak bagian yang bisa dibuka tutup sehingga nilai ergonomisnya tetap terjaga. Bagian yang bisa dibuka tutup menggunakan engsel dan handle. Perlu dipastikan ukuran cover sesuai dengan ukuran luar komponen utama mesin. Gambar simulasi cover mesin dalam software Inventor adalah sebagai berikut :

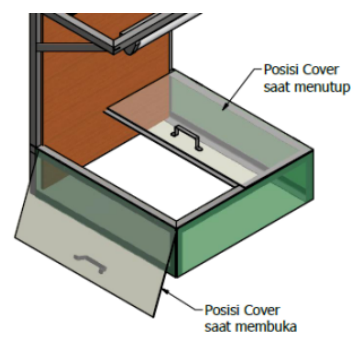

Gambar 11. Desain Cover

\subsection{Penjabaran Desain Safety \& Supporting Equipment Mesin Robot drawing hybrid laser Dapat Mempermudah Operator Dalam Mengoperasikan Mesin}

Desain safety yang berarti pengaman pada mesin robot drawing hybrid laser dibuat agar mesin maupun operator yang mengoperasikan mesin tersebut terhindar dari hal-hal di luar prediksi seperti benda kerja terlepas, komponen mengalami patah dan sebagainya. Dengan adanya cover yang menutup seluruh sisi mesin pada saat beroperasi maka keamanan mesin dan operator akan lebih terjamin. Cover didesain transparan sehingga operator tetap dapat mengontrol kerja mesin dengan baik saat mesin sedang beroperasi.

Supporting equipment atau perangkat pendukung kinerja mesin robot drawing hybrid laser didesain agar penggunaan mesin ini lebih efisien. Mesin diletakkan di atas sebuah meja kerja yang telah dirancang sedemikian rupa sehingga operator yang masih awam pun dapat dengan cepat mempelajari cara pengoperasian mesin tersebut. Hal tersebut karena terdapat panduan atau prosedur kerja yang ditempel pada papan instruksi dengan peletakkan yang proporsional.

Meja mesin yang dibuat dengan sistem moveable akan mempermudah mobilitasi mesin ke tempat di mana meisn akan dioperasikan. Sehingga mesin tidak hanya terpaku pada satu tempat melainkan dapat dipindahkan dengan mudah misal sebagai media pembelajaran di ruang kelas atau laboratorium serta dapat juga dipasang sebagai display di pameran. Lemari yang disematkan pada meja berperan dalam penyimpanan komponen pendukung mesin. Sehingga keamanan dari masing-masing komponen akan tetap terjaga.

\subsection{Proses Rancang Bangun Safety \& Supporting Equipment Pada Mesin Robot drawing hybrid laser}

1. Pembuatan Gambar Assembly

Konsep desain yang telah direncanakan dan dijabarkan pada poin sebelumnya kemudian dituangkan dalam bentuk gambar assembly atau gambar susunan. Gambar assembly saya buat menggunakan software Autodesk Inventor. Mula-mula dilakukan pembuatan gambar part masing-masing komponen. Kemudian gambar disatukan menjadi gambar assembly. Di bawah ini adalah gambar assembly dari safety \& supporting equipment pada mesin robot drawing hybrid laser:

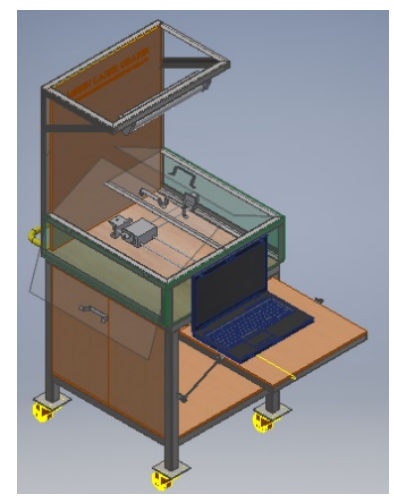

Gambar 11. Assembly Supporting dan Safety Equipment

\section{Pembuatan Gambar Kerja}

Gambar kerja dibuat sebagai pedoman mekanik pada saat proses fabrikasi komponen mesin. Gambar kerja cakupannya lebih detail dibanding gambar assembly. Setiap komponen yang memerlukan proses pembuatan (bukan finish good) dijabarkan ke dalam gambar kerja. Gambar kerja yang dibuat dalam rancang bangun ini mencakup: 


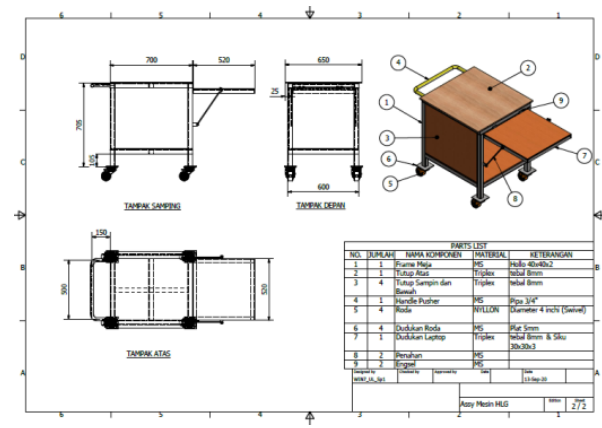

Gambar 12. Detail Frame Meja

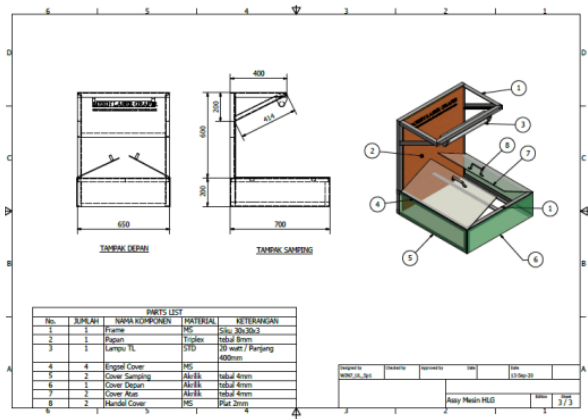

Gambar 13. Detail Papan Intruksi

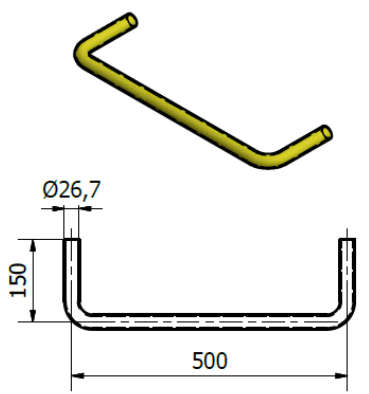

Gambar 14. Detail Handel Pendorong
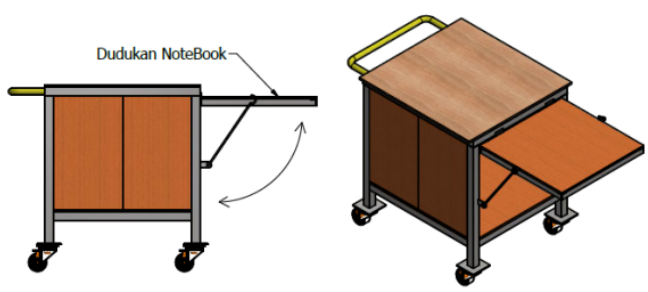

\section{Gambar 15. Detail Dudukan Notebook}

3. Fabrikasi

a. Persiapan Alat dan Material

Pada proses fabrikasi, seperti yang telah dijabarkan pada metode penelitian alat-alat yang digunakan meliputi alat potong, seperangkat mesin pengelasan, alat bantu perakitan dan alat proses finishing. Sedangkan material yang dibutuhkan adalah sebagai berikut : besi hollow ukuran 40 × 40 × $2 \mathrm{~mm}$., papan triplex tebal $9 \mathrm{~mm}$, besi pipsa diameter 3/4inch, besi plat tebal $5 \mathrm{~mm}$, roda nyllon diameter 2inch, besi siku $30 \times 30 \times 3 \mathrm{~mm}$, penahan meja stainless, engsel stainless, skrup, baut dan mur, cat besi, cat kayu, akrilik tebal $4 \mathrm{~mm}$, handle stainless, lampu TL dan kabel .

b. Pemotongan rangka utama

Bahan-bahan rangka utama seperti hollow 40x40x2mm dan siku 30x30x3mm dipotong sesuai dengan ukuran yang ditentukan menggunakan gergaji dan gerinda potong. Pola-pola untuk sambungan masing-masing bagian rangka utama juga dibentuk berdasarkan gambar kerja yang telah dibuat sebelumnya. Tak lupa dipersiapkan dudukan untuk roda dengan bahan plat besi setebal $5 \mathrm{~mm}$. Proses pemotongan rangka utama dapat dilihat pada gambar berikut:

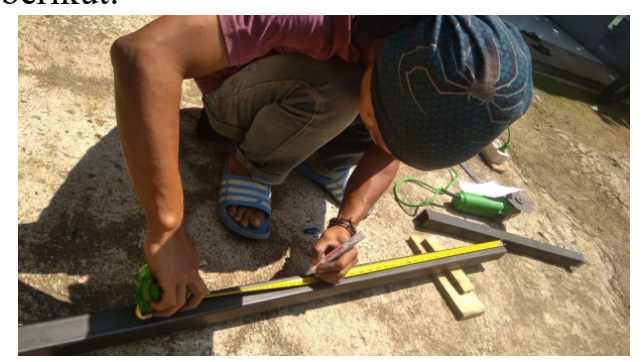

Gambar 15 Proses Pemotongan Bahan

c. Setting dan Welding Rangka Utama

Material rangka utama yang telah dipotong sesuai dengan gambar kerja, kemudian dirakit menjadi satu. Pada proses ini perlu diperhatikan kesejajaran dan ketegaklurusan hasil perakitan. Setelah kualitas perakitan dinyatakan cukup selanjutnya adalah dilakukan pengelasan.

Proses fabrikasi rangka utama dan pengerjaan pengelasan masing-masing sambungan tampak pada gambar berikut : 


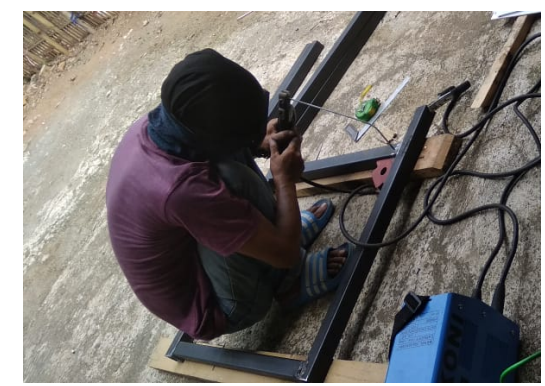

\section{Gambar 16. Proses Pengelasan Rangka Utama}

d. Pemasangan Aksesoris pada Rangka Utama

Aksesoris yang dimaksud adalah komponen-komponen kecil seperti handle, dudukan roda, engsel, bracket penghubung meja dan papan instruksi dan bracket penahan dudukan notebook. Pemasangan aksesoris tersebut dipastikan berfungsi dengan baik.

Setelah semua komponen pada rangka utama terpasang kecuali papan penutup maka selanjutnya dilakukan proses finishing. Proses finishing meliputi penggerindaan sambungan-sambungan las yang kurang rapi, penghalusan sambungan menggunakan amplas, pelapisan papan triplek dan pengecatan baik primer maupun top coating.

\section{e. Pemotongan Papan Triplex dan Finishing}

Setelah rangka utama terbentuk, langkah selanjutnya adalah mempersiapkan bagian atas, bawah dan dinding meja serta papan instruksi. Material papan triplex berbentuk potongan standar dari pasaran yang berukuran besar $(1220 \times 2440 \mathrm{~mm})$ sehingga harus dilakukan pemotongan sesuai dengan kebutuhan rangka utama. Setelah masing-masing ukuran terbentuk maka sebelum dipasang pada rangka utama papan triplex harus difinishing terlebih dahulu menggunakan bahan pelapis.

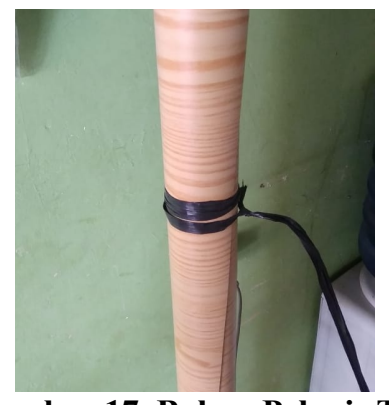

Gambar 17. Bahan Pelapis Triplex

f. Pemasangan Papan Triplex dan Aksesoris pada Rangka Utama

Papan triplex yang telah dipotong kemudian dipasang pada sisi-sisi rangka utama menggunakan paku rivet. Kepala paku rivet dipilih karena akan tampak rata atau tidak menonjol. Papan triplex pada bagian dinding dipasang rata dengan rangka utama sehingga memberikan kesan rapih dan kokoh. Apabila semua sisi telah dipasang papan triplex selanjutnya dilakukan pemasangan roda pada dudukannya.

Berikut adalah gambar papan triplex yang telah dipasang pada rangka utama :

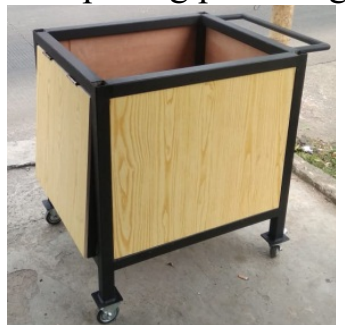

\section{Gambar 18. Pemasangan Triplex Rangka Utama}

Tahap selanjutnya adalah Pemotongan dan Pemasangan Akrilik untuk Cover Mesin. Akrilik lembaran yang dibeli dari pasaran dipotong sesuai dengan ukuran rangka cover. Engsel dan handle cover dipasang pada posisi yang telah ditentukan di gambar kerja. Pastikan fungsi buka tutup cover berjalan dengan baik.

Proses pemasangan cover pada rangka mesin adalah sebagai berikut : 


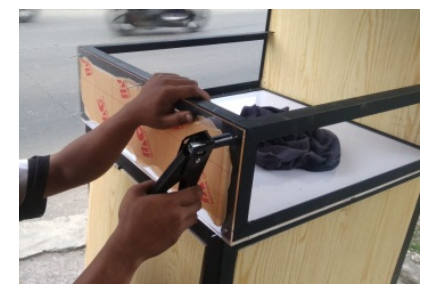

\section{Gambar 19. Pemasangan Cover}

Setelah semua aksesoris terpasang pada rangka utama, tahap akhir dari fabrikasi adalah finishing. Finishing pada tahap ini hanya penyempurnaan pada bagian-bagian yang kurang rapih pada saat proses finishing sebelumnya (sebelum masing-masing komponen dirakit. Berikut ini adalah hasil fabrikasi safety \& supporting equipment mesin robot drawing hybrid laser :

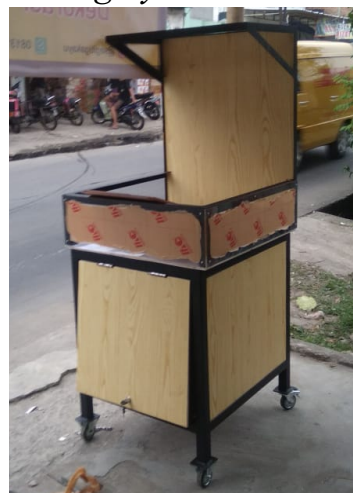

Gambar 20 Hasil Rancang Bangun

Tahap selanjutnya adalah pemasangan mesin utama robot drawing hybrid laser pada meja mesin. Mesin diposisikan sesuai dengan titik yang direncanakan kemudian diberi tanda untuk lubang baut pengikat landasan/base mesin. Selajutnya dibuat lubang tap sesuai ukuran pada dasar mesin barulah mesin diikat dengan baut.

\section{KESIMPULAN}

Dari hasil penelitian yang dilakukan dapat diambil kesimpulan sebagai berikut:

1. Software Inventor pada rancang bangun ini digunakan sebagai media penunjang dalam mensimulasikan rekayasa desain supporting \& safety equipment pada mesin Robot Drawing Hyrid Laser. Dengan software Inventor saya menuangkan bentuk mesin Robot Drawing Hyrid Laser ke dalam bentuk gambar 3D untuk selanjutnya diolah untuk pembuatan simulasi komponen supporting \& safety equipment mesin tersebut.

2. Kemudahan operator dalam mengoperasikan mesin ditunjang oleh desain yang tepat. Pertama desain berupa meja mengemas mesin tersebut ke dalam satu rangkaian mesin yang siap dioperasikan. Dari segi safety, dirancang sebuah cover yang akan melindungi mesin maupun operator pada saat mesin dioperasikan. Terakhir ditambahkan pula papan instruksi sebagai panduan bagi operator yang menjalankan mesin tersebut.

3. Proses rancang bangun ini secara garis besar meliputi pembuatan desain, fabrikasi dan perakitan, serta analisa hasil rancang bangun dan evaluasi.

\section{DAFTAR PUSTAKA}

Diki Muhamad Sobirin, Jana Utama. Perancangan Sistem Multi Computer Numerical Control (CNC) Untuk Plotter Dan Laser Engraving. Jurnal Sistem Komputer, Universitas Komputer Indonesia, 2020.

Djamiko, Riswan Dwi. 2008. Teori Pengelasan Logam. Yogyakarta: UNY

Hafiz Ramadhani, Syafri. Perancangan Dan Analisis Struktur Mekanik Prototipe Laser Cutting. Jom FTEKNIK Volume 5 No.1 April 2018.

Haq, Saiful. Dkk. 2020. Buku Pedoman Penulisan Praktek. Tangerang: Fakultas Teknik UMT

http://digilib.unimus.ac.id/files/disk1/129/jtptunim us-gdl-agussalimc-6426-2-babii.pdf (diakses $1 / 8 / 20$ pukul $22.40 \mathrm{WIB})$

http://eprints.undip.ac.id/45587/3/BAB_II_Tinjaua n Pustaka.pdf (diakses pada $\overline{1 / 8} / \overline{2} 0$ pukul $2 \overline{1} .50 \mathrm{WIB})$

http://indoprinter3d.com/printer-3d/materialprinter-3d/petg-material-gabungankeunggulan-pla-dan-abs/ (diakses pada 20/9/2020 pukul 10.30 WIB)

http://indoprinter3d.com/printer-3d/materialprinter-3d/polylactic-acid-pla/ (diakses pada 5/9/2020 pukul 11.12 WIB)

http://repository.president.ac.id/xmlui/bitstream/ha ndle/123456789/536/003201305022.pdf?seq uence $=1 \&$ isAllowed $=y \quad$ (diakses $5 / 7 / 20$ pukul 15.50 WIB)

http://repository.unpas.ac.id/29790/1/BAB\%20II.p df (diakses pada 8/9/20 pukul 10.15 WIB) 
https://digiwarestore.com/id/digiwarenews/54 memilih-filament-untuk-3d-printer (diakses pada 5/9/20 pukul 07.50 WIB)

https://ee.unud.ac.id/file_pendukung_data_riwayat/ 1448410232.pdf (diakses pada 29/7/20 pukul 23.00 WIB)

https://id.wikipedia.org/wiki/Inkscape (diakses 4/8/20 pukul 08.33 WIB)

https://sujanayogi.wordpress.com/2010/03/05/gam bar-teknik-mesin/ (diakses pada 01/10/20 pukul 20:00)

https://www.academia.edu/15342107/23_Tutorial Inkscape (diakses $4 / 8 / 20$ pukul 08.35 WIB)

https://www.depoinovasi.com/produk-1004stepper-motor-driver-drv8825-komplitheatsink.html (diakses pada 8/8/20 pukul 22.25 WIB)

https://www.depoinovasi.com/produk-971-motorstepper-nema-17-extra-long-bipolar-4-wire3d-printer-cnc.html (diakses pada 14/8/20 pukul 09.00 WIB)

https://www.makerspaces.com/arduino-unotutorial-beginners/ (diakses pada 03/10/20 pukul 18.04 WIB)

https://www.plukme.com/post/pengertian-autocadpengenalan-dan-fungsi-dasar-autocad/ (diakses pada 28/09/20 pukul 19:30)

Irawan, Agustinus Purna. 2007. Diktat Kuliah Mekanika Teknik (Statika Struktur). Jakarta : Fakultas Teknik Universitas Tarumanagara

Munadi, Aulia Syukri, Joga D. Setiawan, Mochammad Ariyanto. Rancang Bangun Prototipe Mesin CNC Laser Engraving Dua Sumbu Menggunakan Diode Laser. Jurnal Teknik Mesin Indonesia, 2018. Vol. 13, No.1.

Sato G. Takeshi, H. N. Sugiarto. 1994. Menggambar Teknik Mesin menurut Standar ISO.Jakarta: PT. Pradnya Paramita 